\title{
Urinary Transforming Growth Factor-beta I as a marker of response to immunosuppressive treatment, in patients with crescentic nephritis
}

\author{
Dimitrios S Goumenos*1, Pantelitsa Kalliakmani1 ${ }^{1}$, Sotiris Tsakas², \\ Florentia Sotsiou $^{3}$ and John G Vlachojannis ${ }^{1}$
}

\author{
Address: ${ }^{1}$ Department of Internal Medicine-Nephrology, University Hospital, Patras, Greece, ${ }^{2}$ Department of Biology, University of Patras, Patras, \\ Greece and ${ }^{3}$ Department of Pathology, General Hospital "Evangelismos", Athens, Greece \\ Email: Dimitrios S Goumenos* - dgoumenos@med.upatras.gr; Pantelitsa Kalliakmani - pantkal@panafonet.gr; \\ Sotiris Tsakas - stsakas@upatras.gr; Florentia Sotsiou - no@email.gr; John G Vlachojannis - johnvl@med.upatras.gr \\ * Corresponding author
}

Published: 20 December 2005

BMC Nephrology 2005, 6:16 doi:10.1 186/147/-2369-6-16

This article is available from: http://www.biomedcentral.com/I47/-2369/6/16

(c) 2005 Goumenos et al; licensee BioMed Central Ltd.

This is an Open Access article distributed under the terms of the Creative Commons Attribution License (http://creativecommons.org/licenses/by/2.0), which permits unrestricted use, distribution, and reproduction in any medium, provided the original work is properly cited.
Received: 31 January 2005

Accepted: 20 December 2005

\begin{abstract}
Background: Crescentic nephritis is characterized by formation of cellular crescents that soon become fibrotic and result in irreversible damage, unless an effective immunosuppressive therapy is rapidly commenced. TGF- $\beta_{\text {I }}$ is involved in the development of crescents through various pathways. The aim of this study was to identify whether the determination of urinary TGF- $\beta_{1}$ levels in patients with crescentic nephritis could be used as a marker of response to treatment.

Methods: Fifteen patients with crescentic nephritis were included in the study. The renal expression of TGF- $\beta_{\text {I }}$ was estimated in biopsy sections by immunohistochemistry and urinary TGF- $\beta_{\text {I }}$ levels were

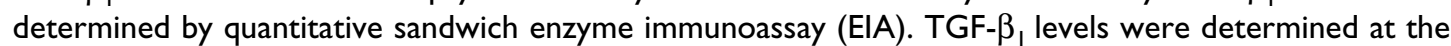
time of renal biopsy, before the initiation of immunosuppressive treatment (corticosteroids, cyclophosphamide and plasma exchange). Twelve patients with other types of proliferative glomerulonephritis and ten healthy subjects were used as controls.

Results: Improvement of renal function with immunosuppressive therapy was observed in 6 and stabilization in 4 patients (serum creatinine from $3.2 \pm 1.5$ to $1.4 \pm 0.1 \mathrm{mg} / \mathrm{dl}$ and from $4.4 \pm 1.2$ to $4.1 \pm$ $0.6 \mathrm{mg} / \mathrm{dl}$, respectively). In 5 patients, with severe impairment of renal function who started on dialysis, no improvement was noted. The main histological feature differentiating these 5 patients from others with improved or stabilized renal function was the percentage patients with poor response to treatment were the percentage of glomeruli with crescents and the presence of ruptured Bowman's capsule and glomerular necrosis. Urinary TGF- $\beta$, levels were significantly higher in patients who showed no improvement of renal function with immunosuppressive therapy $(930 \pm 126 \mathrm{ng} / 24 \mathrm{~h}$ vs. $376 \pm 84 \mathrm{ng} / 24 \mathrm{~h}$,

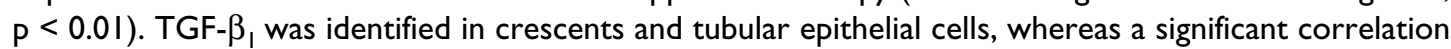

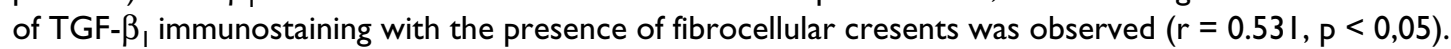

Conclusion: Increased TGF- $\beta$, renal expression and urinary excretion that is related to the response to immunosuppressive therapy was observed in patients with crescentic nephritis. Evaluation of urinary TGF$\beta_{1}$ levels may be proved a useful marker of clinical outcome in patients with crescentic nephritis.
\end{abstract}




\section{Background}

Crescentic nephritis is a type of glomerular disease characterized by crescent formation followed by a rapidly progressive course [1]. It can occur in cases with antibodies against glomerular basement membrane (anti-GBM disease), secondary to other glomerulonephritis and in patients with vasculitis and presence of antineutrophilic cytoplasmic antibodies (ANCA) [1]. Proliferation of parietal cells of Bowman's capsule and macrophages stimulated by cytokines and growth factors is implicated in the development of cellular crescents that soon become fibrotic and result in irreversible damage [2].

TGF- $\beta$ represents a group of $25-\mathrm{kD}$ proteins that are actively involved in the development and differentiation of various tissues and in the healing process after a tissue injury [3]. Three isoforms of TGF- $\beta$ have been identified in mammalian species and TGF- $\beta_{1}$ is the most commonly found in humans [3]. Normally, TGF- $\beta_{1}$ release ceases by feedback mechanisms when the healing process has been completed $[3,4]$. However, if TGF- $\beta_{1}$ release is not switched off, extracellular matrix components (ECM) are accumulated and tissue fibrosis occurs [4]. TGF- $\beta_{1}$ is involved in the development of scarring in crescentic nephritis via activation of myofibroblasts from glomerular parietal epithelial cells [5]. Interstitial myofibroblasts also contribute to the development of fibrous crescents through their migration into the Bowman's space of glomeruli with disrupted capsules [6]. The implication of TGF- $\beta_{1}$ is further supported by the observation of amelioration of histologic damage in experimentally induced anti-GBM nephritis with the blockade of TGF- $\beta_{1}$ action [7].

Increased urinary excretion of TGF- $\beta_{1}$ has been reported in experimentally induced crescentic nephritis that was related to a scarring process leading to end-stage renal disease [8]. Elevated urinary TGF- $\beta_{1}$ levels have been observed in patients with crescentic nephritis and IgA nephropathy that were reduced after treatment with corticosteroids [9]. In the present study the renal expression and urinary excretion of TGF- $\beta_{1}$ were examined in patients with crescentic nephritis in order to identify any potential relation of urinary TGF- $\beta_{1}$ levels with the response to treatment with corticosteroids and cyclophosphamide.

\section{Methods \\ Patients}

Fifteen patients $(7 \mathrm{M} / 8 \mathrm{~F}$, aged from $23-74$ years) with crescentic nephritis due to anti-GBM nephritis $(\mathrm{n}=1)$, diffuse lupus nephritis $(\mathrm{n}=1)$, Henoch Schönlein purpura $(\mathrm{n}=2)$ and ANCA $(+)$ vasculitis $(\mathrm{n}=11)$ were included in the study. The mean serum creatinine and urinary protein at presentation were $4.4 \pm 1.8 \mathrm{mg} / \mathrm{dl}$ and $2.0 \pm 1 \mathrm{~g} / 24 \mathrm{~h}$ respectively (Table 1 ). The expression of TGF- $\beta_{1}$ in the kid-
Table I: Clinical and histological features at presentation.

\begin{tabular}{|c|c|c|}
\hline \multicolumn{3}{|c|}{ Patients with crescentic nephritis $(n=15)$} \\
\hline Gender (male/female) & & $7 / 8$ \\
\hline Age (years) & & \pm 16 \\
\hline Serum creatinine $(\mathrm{mg} / \mathrm{dl})$ & & \pm 1.8 \\
\hline Glomeruli with crescents (\%) & & \pm 20 \\
\hline Cellular crescents (\%) & & \pm 30 \\
\hline Fibrocellular crescents (\%) & & \pm 18 \\
\hline Fibrous crescents (\%) & & \pm 17 \\
\hline Bowman's capsule rupture (\# of pts) & Yes $(n=7)$ & No $(n=8)$ \\
\hline Interstitial inflammation (\# of pts) & Mild $(n=4)$ & Severe $(n=11)$ \\
\hline Interstitial fibrosis (\# of pts) & Mild $(n=6)$ & Severe $(n=9)$ \\
\hline
\end{tabular}

ney was estimated by immunohistochemistry in biopsy sections obtained from all patients whereas TGF- $\beta_{1}$ urinary levels were measured at the time of biopsy and before the administration of immunosuppressive therapy in 12 patients and compared to those observed in 12 patients with other types of proliferative GN (IgA nephropathy $n=$ 7, mesangiocapillary GN $\mathrm{n}=2$ and endocapillary proliferative $\mathrm{GN} \mathrm{n}=3$ ) and in 10 healthy subjects.

All patients were treated with methylprednisolone pulse ( $1 \mathrm{~g} /$ day intravenously for 3 days) followed by oral methylprednisolone $(0.5 \mathrm{mg} / \mathrm{kg} \mathrm{BW} / \mathrm{d})$ and cyclophosphamide either orally $(2 \mathrm{mg} / \mathrm{kg} \mathrm{BW} / \mathrm{d})$ or intravenously $\left(0.7 \mathrm{~g} / \mathrm{m}^{2}\right)$. Plasma exchange (10 sessions of 4 liters each) was also performed in 6 patients. One of these had anti-GBM disease and the other 5 had signs of uremia and needed hemodialysis at presentation. All patients were followed up for at least 3 months after the initiation of therapy. At that time a second measurement of urinary TGF- $\beta_{1}$ levels was performed in most patients with improved or stabilized renal function without the need of dialysis.

\section{Conventional histopathology}

All renal tissues obtained by needle biopsy (14 G) were fixed in $10 \%$ neutral buffered formalin, embedded in paraffin and examined in multiple levels $(4 \mu \mathrm{m})$. Pathologic examination included hematoxylin and eosin (H\&E), periodic acid Schiff (PAS), Masson trichrome and reticulin silver methenamine stain. Crescent organization was evaluated by the presence of reticulin fibers among the cellular components of the crescent. The presence of reticulin allowed identification of fibrocellular and fibrotic crescents. The percentage of the glomeruli surrounded by crescents (cellular, fibrocellular, fibrotic) was counted. Rupture of the Bowman's capsule was also detected on reticulin and PAS sections. The severity of interstitial fibrosis, inflammation and tubular atrophy were also estimated and expressed as mild and severe. 
Table 2: Clinical and histological features of patients with or without improvement of renal function with immunosuppressive therapy.

\begin{tabular}{|c|c|c|c|}
\hline & \multicolumn{2}{|c|}{ Improvement of renal function with treatment } & \multirow[t]{2}{*}{$P$} \\
\hline & YES $(n=6)$ & NO $(n=9)$ & \\
\hline Serum creatinine (mg/dl) & 3.1 & 5.2 & 0.03 \\
\hline Urine protein $(g / 24 \mathrm{~h})$ & 2.4 & 1.7 & NS \\
\hline TGF- $\beta$, urine levels $(\mathrm{ng} / 24 \mathrm{~h})$ & 376 & 930 & 0.001 \\
\hline Glomeruli with crescents (\%) & $56 \%$ & $79 \%$ & 0.03 \\
\hline Cellular crescents (\%) & $37 \%$ & $50 \%$ & NS \\
\hline Fibrocellular crescents (\%) & $44 \%$ & $31 \%$ & NS \\
\hline Fibrotic crescents (\%) & $15 \%$ & $20 \%$ & NS \\
\hline Bowman's capsule rupture and glomerular necrosis [\# of pts (\%)] & $1 / 6(17 \%)$ & $6 / 9(67 \%)$ & $<0.05$ \\
\hline Interstitial inflammation (\# of pts) & $\begin{array}{c}\text { Mild }(n=2) \\
\text { Severe }(n=4)\end{array}$ & $\begin{array}{c}\text { Mild }(n=2) \\
\text { Severe }(n=7)\end{array}$ & NS \\
\hline Interstitial fibrosis (\# of pts) & $\begin{array}{c}\text { Mild }(n=5) \\
\text { Severe }(n=1)\end{array}$ & $\begin{array}{c}\text { Mild }(n=4) \\
\text { Severe }(n=5)\end{array}$ & NS \\
\hline TGF- $\beta_{1}$ immunostaining (\% stained points) & $27 \pm 8$ & $25 \pm 12$ & NS \\
\hline
\end{tabular}

\section{Immunohistochemistry}

TGF- $\beta_{1}$ was detected immunohistochemically on kidney biopsy sections. Briefly, formalin fixed paraffin-embedded kidney sections $(4 \mu \mathrm{m})$ were cut and mounted on gelatinized slides. De-waxed and hydrated sections were processed in a microwave oven for 3 cycles, 5 min each, at $450 \mathrm{~W}$ in citrate buffer, $\mathrm{pH}$ 6.0. After cooling, sections were quenched with $\mathrm{H}_{2} \mathrm{O}_{2} 3 \%$ in methanol for 20 min to inhibit endogenous peroxidase activity. Samples were then treated with Protein Blocking Agent to reduce the non-specific binding of antibodies. Slides were washed in phosphate buffered saline (PBS) and incubated with a polyclonal anti-TGF- $\beta_{1}$ antibody (1:50) (Santa Cruz, USA) for $1 \mathrm{~h}$ at $37^{\circ} \mathrm{C}$, in a humid atmosphere. Following antibody treatment, slides were washed in PBS and incubated for $10 \mathrm{~min}$ with a polyvalent biotinylated secondary antibody (Kwik kit, IMMUNON ${ }^{\mathrm{TM}}$, USA). Slides were then washed in PBS, incubated with streptavidin-peroxidase reagent for $10 \mathrm{~min}$ and washed again with PBS. Visualization of the antigen-antibody complex was achieved by incubating slides in diamine-benzidine (DAB) chromogen solution for $10-20 \mathrm{~min}$, until a satisfactory color development. Finally, slides were washed in water, counterstained with hematoxylin for $2 \mathrm{~min}$ and mounted with resin mounting medium. All steps, except that of the primary antibody, were performed at RT. Control sections were incubated with non-immune rabbit antiserum or processed after the omission of the primary antibody. The severity of TGF- $\beta_{1}$ immunostaining was assessed by morphometric analysis and point counting as previously described [10].

\section{Determination of urinary and plasma TGF- $\beta_{\text {I levels }}$}

The concentration of TGF- $\beta_{1}$ was measured by EIA, according to Honkanen et al. [11]. Microtitre plates (Costar, USA) were coated with $0.1 \mu \mathrm{g} /$ well mouse monoclonal anti-TGF- $\beta$ s antibodies (Genzyme Co., USA) in
$0.05 \mathrm{M} \mathrm{Na}_{2} \mathrm{CO}_{3}$ buffer $\mathrm{pH} 9.0$, by incubating overnight at $4{ }^{\circ} \mathrm{C}$. The wells were washed with PBS, $0.05 \%$ Tween- 20 . $100 \mu \mathrm{l}$ of standard dilutions (R\&D Systems, UK) and undiluted samples were acid-activated $(1 \mathrm{~N} \mathrm{HCl}$, for $2 \mathrm{~h}$ at RT) and neutralized (1.2 N NaOH / 0.5 M HEPES). $100 \mu \mathrm{l}$ of neutralized samples were incubated in the wells overnight at $4{ }^{\circ} \mathrm{C}$. The TGF- $\beta_{1}$ bound onto the wells was then detected with a rabbit polyclonal anti-TGF- $\beta_{1}$ antibody (R\&D Systems, UK) labeled with horseradish peroxidase $(200 \mu \mathrm{l}, 1.5 \mathrm{~h}$ at RT). Peroxidase activity was determined using tetramethylbenzidine (TMB) solution as a substrate (R\&D Systems, UK). The intra-assay and inter-assay coefficients of variation (CV) were 7.4 and $6.3 \%$, respectively. The recovery of TGF- $\beta_{1}$ standards (50 and $100 \mathrm{pg} / \mathrm{ml}$ ) ranged from 83 to $112 \%$. TGF- $\beta_{1}$ urinary excretion was calculated in $\mathrm{ng} / 24 \mathrm{~h}$ and plasma TGF- $\beta_{1}$ concentration was calculated in $\mathrm{ng} / \mathrm{ml}$.

\section{Statistical analysis}

The results were expressed as means \pm SD. Differences of TGF- $\beta_{1}$ excretion in urine between the patient groups were determined by comparison of their mean and median values, using Student's t-test for unpaired data and KruskallWallis non-parametric test. Linear regression analysis was used for correlation between parameters. Multiple regression analysis was applied to determine the predictive value of a given parameter for the progression of renal failure (final serum creatinine). Any p value $<0.05$ was considered as significant.

\section{Results}

\section{General observations/clinical outcome}

Six patients (40\%) with crescentic GN due to anti-GBM nephritis $(\mathrm{n}=1)$, Henoch-Schönlein purpura $(\mathrm{n}=2)$, lupus nephritis $(\mathrm{n}=1)$ and $\operatorname{ANCA}(+)$ vasculitis $(\mathrm{n}=2)$ showed a significant improvement of renal function with immunosuppressive therapy (serum creatinine decreased 

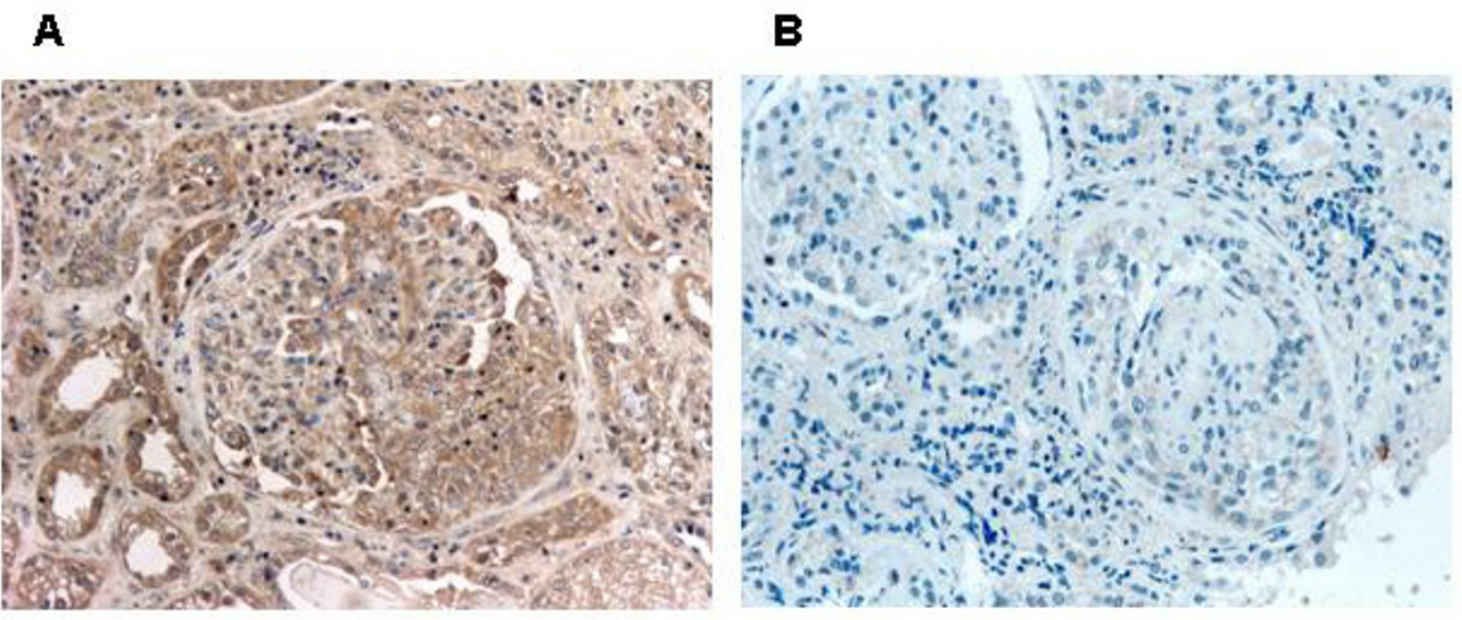

Figure I

Immunohistocemical detection of TGF- $\beta_{\text {I }}$ in the renal tissue. A: Localization of TGF- $\beta_{\text {I }}$ in a crescent and in tubular epithelial cells (dark brown area) (× 200). B: Negative control $(\times 200)$.

from $3.2 \pm 1.5$ to $1.4 \pm 0.1 \mathrm{mg} / \mathrm{dl})$. Stabilization of renal function without the need of dialysis was achieved in 4 patients (serum creatinine before and after treatment 4.4 \pm 1.2 and $4.1 \pm 0.6 \mathrm{mg} / \mathrm{dl}$, respectively).

In 5 patients $(33 \%)$ with $\mathrm{ANCA}(+)$ vasculitis who were presented with signs of uremia no improvement of renal function was observed, even with the addition of plasma exchange in the treatment protocol. The main features differentiating patients who showed improvement of renal function with treatment compared to the others were the serum creatinine at presentation $(3.1 \pm 1.1$ vs. $5.2 \pm 1.5$ $\mathrm{mg} / \mathrm{dl}, \mathrm{p}=0.03)$, the percentage of glomeruli with crescents $(56 \%$ vs. $79 \%, p<0.03)$ and the percentage of patients with ruptured Bowman's capsule and necrosis within the glomeruli $(17 \%$ vs. $67 \%$, p < 0.05) (Table 2$)$. However, urinary TGF- $\beta_{1}$ levels were the most significant parameter differentiating patients with response to treatment from the others $(930 \pm 126$ vs. $376 \pm 84 \mathrm{ng} / 24 \mathrm{~h}, \mathrm{p}$ $<0.01$ ) (Table 2).

A strong predictive value of the intial serum creatinine, percentage of glomeruli with crescents and baseline urinary TGF- $\beta_{1}$ levels for the final serum creatinine was evident. Among those parameters baseline urinary TGF- $\beta_{1}$ levels had the strongest predictive value $\left(\mathrm{R}^{2}=59 \%, \mathrm{p}<\right.$ 0.01).

\section{Immunostaining for TGF- $\beta$ I}

TGF- $\beta_{1}$ was localized within the crescents and particularly in areas with cellular and fibrocellular crescents. It was also identified within the cytoplasm of tubular epithelial cells and in small areas of the interstitium (Fig. 1A). A significant correlation of the extent of TGF- $\beta_{1}$ immunostaining with the presence of fibrocellular crescents was observed $(r=0.531, p<0.05)$. However, no relation of the extent and the intensity of TGF- $\beta_{1}$ expression with the response to treatment was identified (Table 2 ).

\section{Urinary and plasma TGF- $\beta$, levels}

Elevated urinary TGF- $\beta_{1}$ levels were identified in patients with crescentic nephritis compared to healthy individuals $(653 \pm 306$ vs. $310 \pm 140 \mathrm{ng} / 24 \mathrm{~h})$ and to those of patients with other types of proliferative GN (653 \pm 306 vs. $441 \pm$ $131 \mathrm{ng} / 24 \mathrm{~h}, \mathrm{p}<0.05$ ) (Fig. 2). The urinary TGF- $\beta_{1}$ excretion was significantly lower but still higher than normal in patients with crescentic nephritis who showed improvement of renal function with immunosuppressive treatment compared to those who showed no improvement and had either stabilized renal function or end-stage renal disease after treatment $(376 \pm 84$ vs. $930 \pm 126 \mathrm{ng} / 24 \mathrm{~h}, \mathrm{p}$ $<0.01$ ) (Fig. 3). No significant alteration in the urinary TGF- $\beta_{1}$ excretion was observed before and after administration of immunosuppressive therapy in patients who showed improvement (352 \pm 80 vs. $400 \pm 102 \mathrm{ng} / 24 \mathrm{~h}, \mathrm{p}$ $=$ NS) or stabilization of renal function $(960 \pm 81$ vs. 963 $\pm 47 \mathrm{ng} / 24 \mathrm{~h}, \mathrm{p}=\mathrm{NS}$ ).

The plasma TGF- $\beta_{1}$ levels of patients with crescentic nephritis did not significantly differ compared to those of healthy individuals ( $31 \pm 6$ vs. $28 \pm 4 \mathrm{ng} / \mathrm{ml}, \mathrm{p}=\mathrm{NS})$ and were not correlated to the urinary levels. 


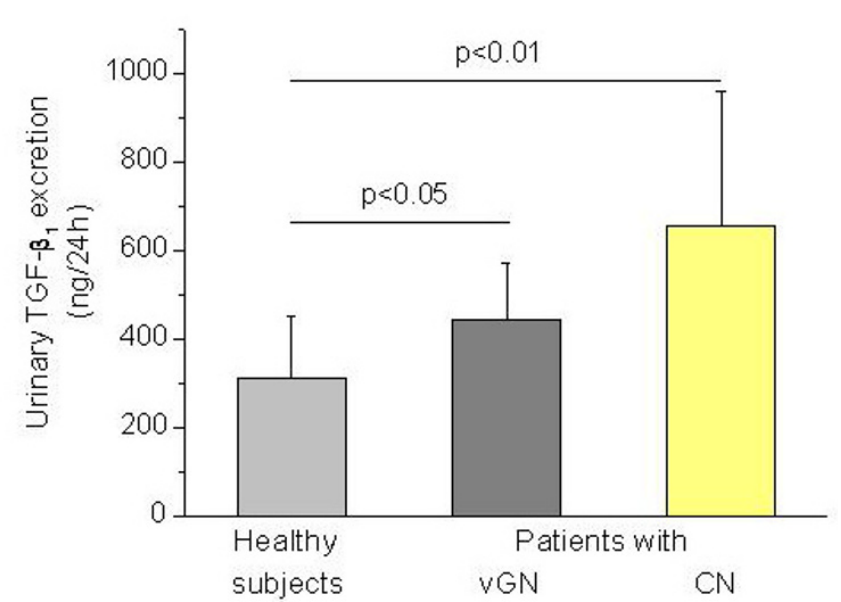

Figure 2

Urinary TGF- $\beta_{\text {I }}$ excretion increased in patients with crescentic nephritis $(C N)(n=15, p<0.01)$ and with various types of proliferative $\mathrm{GN}(\mathrm{vGN})(\mathrm{n}=12, \mathrm{p}<0.05)$, compared to healthy subjects $(n=10)$.

\section{Discussion}

In this study elevated urinary TGF- $\beta_{1}$ levels were observed in patients with crescentic nephritis along with TGF- $\beta_{1}$ expression in cellular and fibrocellular crescents and in the tubulointerstitial area. The excreted amount of TGF- $\beta_{1}$ in the urine was significantly lower in patients who showed a significant improvement of renal function with immunosuppressive treatment in comparison to those with no signs of improvement and it was positively related to the presence of cellular crescents in the renal biopsy.

Several cytokines and growth factors are involved in the development of crescentic nephritis [2]. Activation and proliferation of epithelial cells, monocytes, macrophages, fibroblasts, myofibroblasts and mast cells have been implicated in the formation of crescents and their evolution to fibrosis [12-14]. TGF- $\beta_{1}$ is a pluripotent growth factor that is involved in the pathogenesis of experimental and clinical renal scarring [15-17]. It is implicated in the development of fibrous crescents via activation of myofibroblasts from glomerular and tubular epithelial cells $[5,18]$. In this study TGF- $\beta_{1}$ was identified within cellular and fibrocellular crescents as well as tubular epithelial cells in the renal tissue of patients with crescentic nephritis. Although the factors involved in organization of cellular to fibrotic crescents have not been fully elucidated, a ruptured Bowman's capsule facilitates the progressive organization of cellular crescents by permitting the entry of activated periglomerular $\mathrm{T}$ cells and fibroblasts into

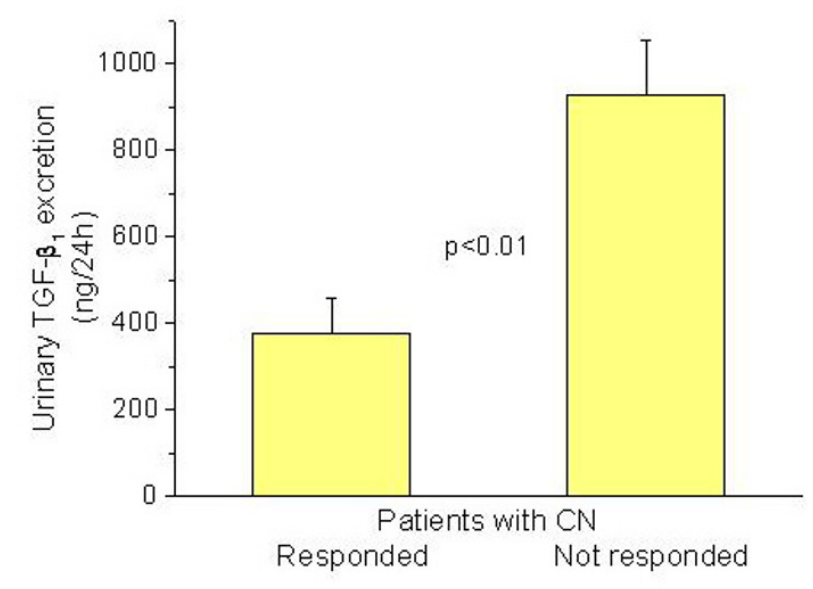

Figure 3

Urinary TGF- $\beta_{\text {I }}$ excretion decreased in patients with crescentic nephritis who responded to immunosuppressive therapy $(n=6)$ compared to those who showed no improvement of renal function $(n=9)$.

Bowman's space $[19,20]$. Ruptured Bowman's capsule was more frequently observed in the glomeruli of our patients with irreversible damage compared to those with improved or stabilized renal function with treatment. We have previously described correlations between percentage of glomeruli with a disrupted Bowman's capsule, fibrous crescents and expression of interstitial myofibroblasts in patients with crescentic nephritis [21]. It is also known that the migration of interstitial myofibroblasts into the Bowman's space through holes in the Bowman's capsule may also contribute to the pathogenesis of glomerulosclerosis [6]. These cells have been identified within crescents demonstrating features of fibrocellular to fibrous organization [13]. Certain proteoglycans such as versican, biglycan and decorin are also involved in the development of fibrous crescents via activation of myofibroblasts and TGF- $\beta_{1}$ [22]. Connective tissue growth factor (CTGF) has been recently shown to be involved in the extracellular matrix production in parietal epithelial cells via TGF- $\beta$ pathway promoting the scarring process in glomerular crescents [23,24].

Increased urinary TGF- $\beta_{1}$ levels have been reported in patients with membranous nephropathy and other types of glomerular disease characterized by the presence of nephrotic syndrome $[10,25]$. This has been related to activation of tubular epithelial cells by proteinuria [26]. Increased urinary TGF- $\beta_{1}$ excretion has been found in patients with insulin-dependent diabetes mellitus and in those with mesangial proliferative glomerulonephritis [27]. Elevated urinary TGF- $\beta_{1}$ activity has been observed in experimentally induced anti-GBM nephritis in rabbits, 
very early in the course of the disease [8]. Urine TGF- $\beta_{1}$ activity increased from day 2 onwards peaked on day 7 and returned to normal levels after day 14 . This time course was identical to that observed for the renal cortical production of TGF- $\beta_{1}$ and it was related to the development of fibrotic lesions [8]. These results suggest that measurement of urinary TGF- $\beta_{1}$ levels at certain stages of the disease may be more useful than serum creatinine in predicting the progression to end stage renal disease and serve as a noninvasive adjunct in monitoring response to therapy [8]. Elevated urinary TGF- $\beta_{1}$ levels that were correlated to the degree of crescent formation have been described in patients with crescentic nephritis and IgA nephropathy. These levels were significantly reduced after treatment with corticosteroids [9]. In this study, increased urinary TGF- $\beta_{1}$ levels and TGF- $\beta_{1}$ renal expression within cellular and fibrocellular crescents were found in patients with crescentic nephritis. These results are in agreement with those observed in experimentally induced anti-GBM nephritis and are suggestive of activation of TGF- $\beta_{1}$ during an early stage of the disease. At this stage the elevated urinary TGF- $\beta_{1}$ levels might be due to increased local production from inflammatory cells within the glomeruli. However, at a latter stage during the organization of crescents increased production of TGF- $\beta_{1}$ from myofibroblasts is possible. It is known that during the development of cellular crescents the administration of immunosuppressive therapy can restrict the glomerular damage whereas the development of fibrotic crescents suggests that permanent damage has occurred. In patients who showed a significant improvement of renal function with immunosuppressive treatment the excreted amount of TGF- $\beta_{1}$ in the urine was significantly lower compared to that observed in patients with no improvement of renal function. Thus, urinary TGF- $\beta_{1}$ levels may be a marker of acute glomerular inflammation associated with crescent formation and may represent the severity of glomerular involvement and the potential response to immunosuppressive drugs towards inhibition of the development of permanent damage. According to our results, very high urinary TGF- $\beta_{1}$ levels are followed by a poor response to immunosuppressive therapy. Furthermore, in patients with poor response to therapy (serum creatinine $4 \mathrm{mg} / \mathrm{dl}$ ) the urinary TGF- $\beta_{1}$ levels remain high even after the administration of immunosuppressive therapy. This suggests that very high urinary TGF- $\beta_{1}$ levels probably represent the development of irreversible damage in the renal tissue of patients with crescentic nephritis. However, since the number of patients examined is not large, further research is required in order to establish urinary TGF- $\beta_{1}$ levels as a marker of the clinical outcome and response to treatment in patients with crescentic nephritis.

\section{Conclusion}

These findings provide evidence that the determination of urinary TGF- $\beta_{1}$ levels in patients with crescentic nephritis gives information about the organization of cellular to fibrous crescents and the response to immunosuppressive therapy. However, further research is necessary in order to establish urinary TGF- $\beta_{1}$ levels as a useful marker of the disease activity and define the exact role of TGF- $\beta_{1}$ in the progression of crescentic nephritis.

\section{Competing interests}

The author(s) declare that they have no competing interests.

\section{Authors' contributions}

DS Goumenos: Design and supervision of the study

P Kalliakmani: Patients follow up and sample collection

S Tsakas: Immunohistochemical and ELISA experiments

F Sotsiou: Renal biopsies

JG Vlachojannis: Design of the study

\section{References}

I. Couser WG: Rapidly progressive glomerulonephritis: Classification, pathogenetic mechanisms and therapy. Am J Kidney Dis 1988, I I:449-464.

2. Atkins RC, Nicolic-Paterson DJ, Song Q, Lan HY: Modulators of crescentic glomerulonephritis. J Am Soc Nephrol 1996, 7:227I-2278.

3. Lawrence $A D$ : Transforming growth factor- $\beta$ : An overview. Kidney Int 1995, 47(Suppl 49):S 19-S23.

4. Basile DP: The transforming growth factor beta system in kidney disease and repair: recent progress and future directions. Curr Opin Nephrol Hypert 1999, 8:2 I-30.

5. Ng YY, Fan JM, Mu W, Nikolic-Paterson DJ, Yang WC, Huang TP, Atkins RC, Lan HY: Glomerular epithelial-myofibroblast transdifferentiation in the evolution of glomerular crescent formation. Nephrol Dial Transpl 1999, 14:2860-2872.

6. EI Nahas AM: Glomerulosclerosis: intrinsic and extrinsic pathways. Nephrol Dial Transplant 1996, I I:773-777.

7. Zhou A, Ueno H, Shimomura M, Tanaka R, Shirakawa T, Nakamura $H$, Matsuo M, lijima K: Blockade of TGF- $\beta$ action ameliorates renal dysfunction and histologic progression in anti-GBM nephritis. Kidney Int 2003, 64:92-10I.

8. Noh JW, Wiggins R, Phan SN: Urine Transforming Growth Factor $-\beta$ activity is related to the degree of scarring in crescentic nephritis in the rabbit. Nephron 1993, 63:73-78.

9. Hamaraki R, Kiyoshi T, Fujisawa M, et al.: Steroid therapy and urinary Transforming Growth Factor- $\beta_{\mathrm{I}}$ in IgA nephropathy. Am J Kidney Dis 2001, 38:1 191-11 98.

10. Williams MA, Lowrie Jl: Fixation of tissues for morphometric study. In Nephrotoxicity in Experimental and Clinical Situations Edited by: Bach FH, Lock EA. Dordrecht, Part I Martinus Nijhoff; 1987:141-166.

II. Honkanen E, Teppo AM, Tornroth T, Groop PH, Groonhagen-Riska C: Urinary transforming growth factor $-\beta_{1}$ in membranous glomerulonephritis. Nephrol Dial Transplant 1997, I 2:2562-2568.

12. Holzman BL, Wiggins RC: Glomerular crescent formation. Semin Nephrol I991, I I:346-353.

13. Alpers CE, Hudkins KL, Floege J, Johnson R: Human renal cortical interstitial cells with some features of smooth muscle cells participate in tubulointerstitial and crescentic glomerular injury. J Am Soc Nephrol 1994, 5:20 I-2 I0. 
14. Toth T, Toth-Jakatics R, Jimi S, Ihara M, Urata H, Takebayashi S: Mast cells in rapidly progressive glomerulonephritis. J Am Soc Nephrol 1999, I0:1498-1505.

I5. Border WA, Okuda S, Languino L, Sporn MB, Ruoslahti : Suppression of experimental glomerulonephritis by antiserum against transforming growth factor- $\beta_{1}$. Nature 1990, 346:37I-374.

16. Yamamoto T, Noble NA, Cohen AH, Nast CC, Hishida A, Gold LI, Border WA: Expression of TGF- $\beta$ in human glomerular disease. Kidney Int 1996, 49:46 |-469.

17. Goumenos DS, Tsamandas AC, Oldroyd S, Sotsiou F, Tsakas S, Petropoulou C, Bonikos D, El Nahas AM, Vlachojannis JG: Transforming growth factor- $\beta_{1}$ and myofibroblasts: $A$ potential pathway towards renal scarring in human glomerular disease. Nephron 200I, 87:240-248.

18. Fan JM, Ng YY, Hill PA, Nikolic-Paterson DJ, Mu W, Atkins RC, Lan HY: Transforming growth factor- $\beta$ regulates tubular epithelial-myofibroblast transdifferentiation in vitro. Kidney Int 1999 , 56: 1455-1467.

19. Lan HY, Nikolic-Paterson DJ, Atkins RC: Involvement of activated periglomerular leukocytes in the rupture of Bowman's capsule and glomerular crescent progression in experimental glomerulonephritis. Lab Invest 1992, 67:743-75I.

20. Ophascharoensuk Y, Pippin JW, Gordon KL, Shankland SJ, Couser WC, Johnson RJ: Role of intrinsic renal cells versus infiltrating cells in glomerular crescent formation. Kidney Int 1998, 54:4l6-425

21. Goumenos D, Tsomi K, latrou C, Oldroyd S, Sungur A, Papaioannides D, Moustakas G, Ziroyannis P, Mountokalakis T, El Nahas AM: Myofibroblasts and the progression of crescentic glomerulonephritis. Nephrol Dial Transplant 1998, I3:|652-I66I.

22. Stokes MB, Hudkins KL, Zaharia V, Taneda S, Alpers CE: Up-regulation of extracellular matrix proteoglycanes and collagen type I in human crescentic glomerulonephritis. Kidney Int 200I, 59:532-542.

23. Kanemoto K, Usui J, Tomari S, Yokoi H, Mukoyama M, Aten J, Weening J], Nagata M: Connective tissue growth factor participates in scar formation of crescentic glomerulonephritis. Lab Invest 2003, 83:1615-1625.

24. Kanemoto K, Usui J, Horita S, Harada A, Koyama Aten J, Weening J], Negata M: In situ expression of connective tissue growth factor in human crescentic glomerulonephritis. Virchows Arch 2004, 444:257-263.

25. Goumenos DS, Tsakas S, El Nahas AM, Alexandri S, Oldroyd S, Kalliakmani P, Vlachojannis JG: Transforming Growth Factor beta- I in the kidney and urine of patients with glomerular disease and proteinuria. Nephrol Dial Transpl 2002, I 7:2 I 45-2I 52.

26. Remuzzi G: Nephropathic nature of proteinuria. Curr Op Nephrol Hypert 1999, 8:655-663.

27. De Muro P, Faedda R, Fresu P, Masala A, Cigni A, Concas G, Mela MG Satta A, Carcassi A, Sanna GM, Cherchi GM: Urinary transforming growth factor-betal in various types of nephropathy. Pharmacol Res 2004, 49:293-298.

\section{Pre-publication history}

The pre-publication history for this paper can be accessed here:

http://www.biomedcentral.com/1471-2369/6/16/prepub

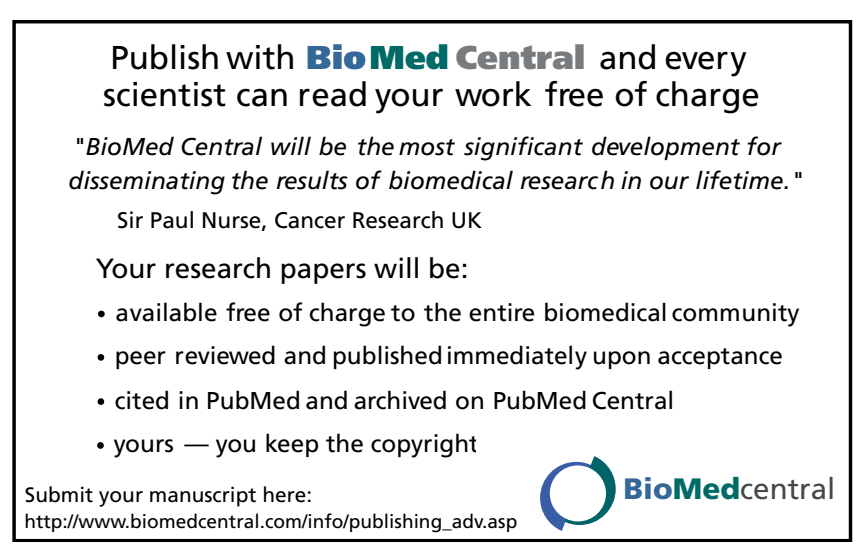

